\title{
Assessment of Some Salivary Biomarkers in Sample of Children with Attention Deficit Hyperactivity Disorder
}

\author{
Mohammad Faris B.D.S ${ }^{1}$, Shatha Q. Jawad BDS, MSc, PhD $^{2}$ \\ ${ }^{1}$ MSc Student in Oral Physiology \\ ${ }^{2}$ Assistant Professor Physiology, College of dentistry, Baghdad University, Iraq
}

\begin{abstract}
Attention Deficit Hyperactivity Disorder (ADHD) is a very common problem in childhood and any one deal with children is likely to encounter it. It is multifactorial disorder which results from combination of environmental and genetic factors. If children with ADHD are identified early and appropriate interventions are made the problem is likely to be mitigated. Aims of the study: This study is the first to assess the psychosocial endocrine hormonestress in a sampleof Iraqi primary school children experiencing attention deficit hyperactivity disorder (ADHD) compared against normal pupilsand provide further information of the role of some salivary biomarkers. Materials and methods: The study sample included 85 school males pupils, with the age ranged between 8-12 years, selected from primary schools, at Al-Qadisiyah city. Revised version of Rutter Child Behavior Questionnaire has been used as a means for identification of children with ADHD and children with prosocial(control).Assess the DMFT/dmft index, flow rate, serological and hormonal analysis were made to estimate peroxidase and alpha-amylase levels in saliva of 50 ADHD pupils and 35 normal pupils as control group, using Indirect enzyme linked immuonosorbent assay. This study was conducted during the period from the beginning of 2015 to the end of 2016. Results: In Oral Health Status investigation we found the level of DMFThighly significant increased ( $p=0.001$ ) in ADHD pupils than in control group (1.488 vs. 1.031). While the dmft level was not significant (p>0.05), in ADHD group compared with control group (1.820 vs. 1.314).In Physiological investigation we found the level of salivary flow rate in ADHD group and controls group wasno significantly difference $(0.186 \mathrm{ml} / \mathrm{min})$ in $A D H D$ group when compared to control group $(0.183 \mathrm{ml} / \mathrm{min})$,at p-value (p>0.05)and.In hormonal and biochemical investigation we found the Salivary Alpha-amylase levels are highly significant increased $(p=0.01)$ in ADHD pupils (253.364 unit $\backslash$ L)than in control group $(136.863$ unit $L)$. Also the levels of the Salivary peroxidase were highly significant increased $(p=0.01)$ among $A D H D$ pupils $(0.369$ unit $\backslash$ L) compared with control group $(0.247$ unit $\backslash L)$. Conclusion:It was concluded; the percentage of the dental caries in ADHD among primary schools children is high in the studied schools and may be due to the changes in the levels of hormones. Due to the little information about this disorder, this study is considered as important baseline data for ADHD in Iraq.
\end{abstract}

\section{Introduction}

Attention deficit hyperactivity disorder (ADHD) is a problem of overactive, not being able to focus, unable control behavior, or a combination of these, despite being one of the most common childhood psychiatric disorder of neurodevelopmental type, patient suffer from ADHD usually have impaired function in many aspect for examaple family and school relationships tho in turn performance and school achievement, and can continue through adolescence or adulthood (1). ADHD is not only one of the important causes that necessitate a consultation of health professionals but if it is not recognized and managed early can cause school failure, loss of self-confidence, anti-social behavior and substance abuse .also it has been reported that childhood ADHD represent the reason behind adulthood disorder as a result some specialist conclude that antisocial behaviors and ADHD represent 2 aspect in the same disorder $(\mathbf{2 ; 3})$.

Etiology of ADHD is not clear and the pathophysiology is not completely understood.

There are several evidences for involvement of the neurotransmitter system in the pathogenesis (4), but available data suggest the possible involvement of multiple factors such as neurochemical deficits, cerebral circulatory impairments and subtle foetal and perinatal brain damage due to toxic, metabolic or physical insult. Stress and anxiety have also been found to complicate clinical manifestations of ADHD (5). It is thought to be caused by complex combination of genetic and environmental changes which cause temporary fluctuation in circulating hormone level influence behavior (6).It is widely accepted that psychological stress could produce physiological effects. Two primary systems are particularly involved in setting on the stress response, hypothalamus-pituitary-adrenocortical axis (HPA) and sympatho-adrenomedullary (SAM) system. The activation of HPA causes an increase in cortisol secretion in the adrenal cortex, while the activation of SAM causes an increase in salivary alpha-amylase (sAA)(7).It is important to examine individual differences in the level of stress hormones like salivary alpha-amylase, in order to establish the medical methods of diagnosis and prediction of future neuropsychiatric disruptions associated with impulsivity (8).

\section{Materials and Methods}

Fifty pupils (50) with the age ranged from 8 to 12 years, all of them were suffering from ADHD who have been diagnosed according Rutter Child Behaviour Questionnaire, were enrolled in this study after obtaining the consent from their families. And the purpose of the study was explained to them to assure full cooperation. Thirty fivepupils (35) characterized by prosaically behavior, were correspondent to the first group (ADHD group) in their age and gender, selected from the same schools.All subjects should not suffer from any systemic disease or periodontitis after examination, taking history from their families and clinical examination by pediatric specialists. Three $\mathrm{ml}$ of 


\section{International Journal of Science and Research (IJSR) \\ ISSN (Online): 2319-7064}

Index Copernicus Value (2015): 78.96 | Impact Factor (2015): 6.391

unstimulated (resting) whole saliva samples were collected under resting conditions between 9.0-12.0 A.M. patients were asked to rinse their mouth with water and to generate saliva in their mouth and drool into a wide test tube. And calculate the time for collection by divided the volume of saliva on time obtain salivary flow rate. After that the saliva was centrifuged at $(3000 \mathrm{rpm})$ for 10 minutes. The resulting supernatant was stored at $-20{ }^{\circ} \mathrm{C}$ in polyethylene tubes until assayed.Salivary $\alpha$-amylase and peroxidase were measured by colorimetric method.

Statistical analysis Data description, analysis and presentation were performed using two computer software programs as they Statistical Package for social Sciences (SPSS version 21). Statistical analysis can be classified into two categories:

\section{1-Descriptive Analysis:}

A- Mean, SD and range for numeric variables (Quantitative).

B-Graphs: Scatter plot graphs for correlation between two variables..

\section{2- Inferential analysis:}

A-Levene test: test the equality of variances between two groups.

B-Two independent sample T-test: Test the significant differences of means between two groups.

Level of significance can be tested as probability of error (pvalue):

- Not Significant at $\mathrm{P}>0.05$

- Significant at $\mathrm{P}<0.05$

- Highly significant at $\mathrm{P}<0.01$.

\section{Results}

In Oral Health Status investigation we found the level of DMFThighly significant increased $(\mathrm{p}=0.001)$ in ADHD pupils than in control group (1.488 vs. 1.031)as in (Table1).While the dmft level was not significant ( $p>0.05$ ), in ADHD group compared with control group (1.820 vs. 1.314)as in (Table 2).In Physiological investigation we found the level of salivary flow rate in ADHD group and controls group wasno significantly difference $(0.186 \mathrm{ml} / \mathrm{min})$ in ADHD group when compared to control group $(0.183 \mathrm{ml} / \mathrm{min})$, at $\mathrm{p}$-value ( $>>0.05)$ as in(Table 3). In hormonal and biochemical investigation we found the Salivary Alpha-amylase levels are highly significant increased $(\mathrm{p}=0.01)$ in ADHD pupils (253.364 unit $\mathrm{L}$ )than in control group (136.863 unit $\mathrm{L}$ )as in the (Table 4). Also the levels of the Salivary peroxidase were highly significant increased $(\mathrm{p}=0.01)$ among ADHD pupils (0.369 unitlL) compared with control group ( 0.247 unit $\backslash \mathrm{L})$ as in (Table 5).

Table 1: Difference DMFT in ADHD group and control group

\begin{tabular}{|c|c|c|c|c|c|}
\hline Groups & $\mathrm{N}$ & Mean & SD & T.test & P value \\
\hline ADHD & 50 & 2.780 & 1.329 & 3.328 & $0.001(\mathrm{HS})$ \\
\hline Control & 35 & 1.800 & 1.346 & & \\
\hline
\end{tabular}

Table 2: Difference dmft in ADHD group and control group

\begin{tabular}{|c|c|c|c|c|c|}
\hline Groups & $\mathrm{N}$ & Mean & SD & T.test & P value \\
\hline ADHD & 50 & 1.820 & 1.848 & 1.367 & 0.173 (HS) \\
\hline Control & 35 & 1.314 & 1.367 & & \\
\hline
\end{tabular}

Table 3: Difference in Salivary flow rate in ADHD group and control group

\begin{tabular}{|c|c|c|c|c|c|}
\hline Groups & $\mathrm{N}$ & Mean & SD & T.test & P value \\
\hline ADHD & 50 & 0.186 & 0.047 & 0.367 & $0.712(\mathrm{HS})$ \\
\hline Control & 35 & 0.183 & 0.039 & & \\
\hline
\end{tabular}

Table 4: Difference in Salivary Alpha-amylase in ADHD group and control group

\begin{tabular}{|c|c|c|c|c|c|}
\hline Groups & $\mathrm{N}$ & Mean & SD & T.test & P value \\
\hline ADHD & 50 & 253.364 & 96.081 & 6.659 & $0.000(\mathrm{HS})$ \\
\hline Control & 35 & 136.863 & 65.186 & & \\
\hline
\end{tabular}

Table 5: Difference in Salivary peroxidase in ADHD group and control group

\begin{tabular}{|c|c|c|c|c|c|}
\hline Groups & $\mathrm{N}$ & Mean & SD & T.test & P value \\
\hline ADHD & 50 & 0.369 & 0.114 & 5.921 & 0.000 \\
\hline Control & 35 & 0.247 & 0.052 & & \\
\hline
\end{tabular}

\section{Discussion}

\section{Oral health status (DMFT, Dmft and salivary flow rate):}

In our study highly significant differences were observed in the DMFT mean level between the two groups, such findings are similar to what's seen in other studies such as (9) found that the patient with ADHD had significantly higher DMFT than in control group and (10) found that the prevalence of caries in the permanent teeth of those who suffer from ADHD was higher than that in control.

While (11) didn't find any significant differences in the DMFT between the ADHD and control groups. Our results can be attributed to many factors such as, poor oral health or ADHD changes could be results of poor diatary or tooth brushing habits or impaired salivary capacity. The family of those patients usually give them high calorie diet as a reward ,or those children may have impaired attention and unable to stay focused, which may result in non-effective teeth care , with poor parent child relation might influence daily tooth brushing habits. Also ADHD drugs have impotant influence of xerostomia and decrease salivary protective properties, resulting in higher risk of tooth decay, the intake of soft drinks to reduce mouth dryness (12). And infrequent dental visit and behavior management problems may represent important cause for worsening the condition (13). The difference in dmft in ADHD and control group in this study was not significant which is similar to what is seen in the study of (9) and (14) who stated that, ADHD children in the age between six to ten years had notably more dental caries in deciduous and permanent teeth, but on an average mean caries experience in Primary dentition didn't varySignificantly between ADHD Children and non ADHD control when we look for the prevalence of caries and parents of each child were asked to complete a questionnaire regarding the Childs demographic information, past medical history, diatary and oral health habits. 


\section{International Journal of Science and Research (IJSR) \\ ISSN (Online): 2319-7064}

Index Copernicus Value (2015): 78.96 | Impact Factor (2015): 6.391

But (15) reported highly significant difference in $\mathrm{dmft}$ between ADHD and control group. In the our study the absence statistically significant variation between the groups concerning caries prevalence may be attributed to many causes to mention is: the small number of children in the studied group. Second the DMFS mean value was larger, and the frequency of individuals without caries was smaller, in the ADHD children as compared with the control group, but the variation were not significant as noted in(14).In our study there was no significant difference between ADHD and control groups salivary flow rate. This result is similar to those of the previous studies like (9) and (16) who reported no difference in the salivary flow rate between ADHD group and control group. While (17) and (11) found that all children with ADHD had significantly lower non stimulated salivary flow rate. The result found in our study may result from the fact that methylphenidate may cause xerostomia and reduce the unstimulated salivary flowrate in the ADHD group treated with this medication as found by (18) and since the children with ADHD in our study weren't on such medication we didn't expect to see a change in salivary flow rate.

\section{Hormonal and biochemical parameters (salivary peroxidase and salivary alpha amylase) \\ Salivary peroxidase according to the result of our study shows highly significant increase in ADHD group compared to control group this result is coinciding to another study done by (19). While (20) who found significant difference in ADHD and control group in the salivary peroxidase. Only one of the oxidative stress variables were assessed which result in an inadequate assessment of the condition also it is obvious that the noticed amount of the salivary markers characteristically show variable concentration among studies with such a difference, Variable results from the studies were expected .The causes for such a difference are both biological and technical. Different protocols and materials are used $(\mathbf{2 1 ; 2 2})$. Our study reveals many pre analytic aspects which influence the markers of oxidative stress under study such as Methods used when collecting the saliva, time of collection, intake of antioxidants, oral hygiene habits etc. $(\mathbf{2 3} ; \mathbf{2 4})$. In regard to salivary a-amylase level ADHD and control groups the results shows highly significant increase in a statistical analysis was done for ADHD group, according to the result the total protein shows highly significant increase in ADHD group compared to control group.To the best of our knowledge no previous Iraqi study have been devoted to this area and reports have been scarce however a growing interest in salivary marker as a diagnostic tool warrants further research.}

\section{References}

[1] Alamanac, B.; Nutt, D.; Adam, M.; Asherson, P.; Bazire, S.; Coghil, D.; Heal, D.; Muller, U.; Nash, J.; Santosh, P.; Sayal, K.; Sonuiga,,B. and Young, S. (2014).:" Evidence-based guidelines for the pharmacological management of attention deficit hyperactivity disorder". Br. J. psychopharmacology, 20:1-5.

[2] Association Psychiatry American (APA). (2013)." Diagnostic and Statistical Manual of Mental Disorders". 5th ed. Arlington, American Psychiatric Publishing, 5965.

[3] National Institute of Mental Health (NIMH). (2013)." Attention Deficit Hyperactivity Disorder (ADHD)". United States: National Health, 25:1-17.

[4] Faraone, S. and Mick, E. (2010). :" Molecular genetics of attention deficit hyperactivity disorder". Psychia. Clin. North. Am., 33: 159-180 .

[5] Pakkila, F. ; Pouta, A.; Hartikainen, A.; Ruokonen, A.; Surcel, H.; Bloigu, $\quad$ A.; Vääräsmäki, M.; Järvelin, M.; Moilanen, I. and Suvanto, E. (2014)."The Impact of Gestational Thyroid Hormone Concentrations on ADHD Symptoms of the Child". J. Clin. Endocrinol. Metab., 99:1-8.

[6] Wang, L. and Chen, C. ( 2013 ). "The potential role of neuroendocrine in patients with Attention deficit hyperactivity disorder". J. Psychiol., 37: 1-11.

[7] Nater UM1, Rohleder N. (2009)." Salivary alphaamylase as a non-invasive biomarker for the sympathetic nervous system".current state of research. May;34(4):486-96. doi: 10.1016/j.

[8] Takahashi, K. ;Myawaki, D. and Swzuki, F. (2007)." Hyperactivity and comorbidity in Japannese children with attention- deficit/hyperactivity disorder". Psychia. Clin. NeuroSci., 61:255-62.

[9] Grooms MT, Keels MA, Roberts MW, McIver FT (2005).:" Caries experience associated with attentiondeficit hyperactivity disorder".JClinPediatr Dent 30:3-8

[10] Broadbent JM, Thomson WM (2004).: "For debate: problems with the DMF index pertinent to dental caries data analysis". Community Dent Oral Epidemiol. 33: 400-9. doi:10.1111/j.1600-0528.2005.00259.x. PMC 1388190 . PMID 16262607.

[11] Hidas A1, Noy AF, Birman N, Shapira J, Matot I, Steinberg D, Moskovitz M.2011.:" Oral health status, salivary flow rate and salivary quality in children, adolescents and young adults with ADHD". Arch Oral Biol.: 56(10):1137-41.

[12]ROBINSON RG, JORGE RE. (2009)."Kaplan and Sadock'sComprehensiveTextbook of Psychiatry", 9th edn. New York: LippincottWilliams and Wilkins,; 3244, 3267, 3580-3586.

[13] SKARET E, RAADAL M, KVALE G, BERG E. (2000) ."Factors related to missed and cancelled dental appointments among adolescents in Norway". Eur J Oral Sci; 108: 175-183

[14]BLOMQVIST M, HOLMBERG K, FERNELL E, EK U, DAHLLOF G. (2007)." Oral health, dental anxiety, and deficit.hyperactivity disorder". Eur J Oral Sci 114:385-390.

[15] Chandra P, Anandakrishna L, Ray P. (2009).:" Caries experience and oral hygiene status of children suffering from attention deficit hyperactivity disorder. J ClinPediatr Dent".;34(1):25-9.

[16] Archana， E.;Pai ， P.;Praphu,B.;Revathi ; Shenony;Prabhu,k. and Rao,a.(2011). :"Altered biochemical parameter in Saliva pediatric attention deficit hyperactive disorder".

[17] Sandra,S.;S.;Rosenberg;RDH;MDH;Kumar,PHD;Nanc y J. Williams;RDH,EdD(2014)." Attention deficit hyperactive disorder medication and dental caries in children". 


\section{International Journal of Science and Research (IJSR) \\ ISSN (Online): 2319-7064}

Index Copernicus Value (2015): 78.96 | Impact Factor (2015): 6.391

[18] Medori R, Ramos-Quigora JA, Casas M, Kooij JJS, Niemela“ A,Trott G-E, et al.( 2008).:" A randomized placebo-controlled trial ofthree fixed dosages of prolonged-release OROSmethylphenidate in adults with attention-deficithyperactivity disorder". BiolPsychiatry ;63(10):981-9.

[19] Archana E, Pai P, Prabhu BK, Shenoy RP, Prabhu K, Rao A (2012).:"Altered biochemical parameters in saliva of pediatric attention deficit hyperactivity disorder". Neurochem Res 37:330334.doi:10.1007/s11064-011-0616-x

[20] Ruchi K, Anil Kumar S, Sunil G, Bashir A, Prabhat S (2011). "Antioxidant activity in children with ADHD - a comparison in untreated and treated subjects with normal children".

[21] Palmieri, B., and Sblendorio ,V.(2007a)."Oxidative stress tests: overview on reliability and use ".PartI. Eur .Rev. Med. Pharmacol .Sci. 11, 309-342.

[22] Wang,Z.,Wang,Y.,Liu,H.,Che,Y.,Xu,Y.,andE,L.(2015a) ."Ager elated variations of protein carbonyls in human saliva and plasma, is saliva protein carbonyls an alternative biomarker rof aging? Age (Dordr)". 37:9781.doi: 10.1007/s11357-015-9781-1

[23] Kamodyová, N., and Celec, P.(2011)."Salivary markers of oxidative stress and salivette collection systems". Clin.Chem.Lab.Med.

49,1887-1890.doi: 10.1515/cclm.2011.677

[24] Kamodyová,N.,Táthová,L.,andCelec,P.(2013).:"Salivar y markers of oxidative stress and antioxidant status :influence of external factors". Dis. Markers 34, 313321.doi: $10.1155 / 2013 / 341302$

Volume 6 Issue 7, July 2017 www.ijsr.net 